\title{
PATIENT SUPPORT PROGRAMS - IMPACT ON THE ADHERENCE OF RHEUMATOID ARTHRITIS TREATMENT WITH CERTOLIZUMAB PEGOL
}

Mariana Papaléo Rosim (MAPESolutions, São Paulo, SP, Brasil), Mayari Eika Ishimura (UCB Biopharma, São Paulo, SP, Brasil), Guilherme Benedini Damian (UCB Biopharma, São Paulo, SP, Brasil), Bruno Salgado Riveros (MAPESolutions, São Paulo, SP, Brasil)

\section{BACKGROUND}

Certolizumab pegol (CZP) is a biologic disease-modifying antirheumatic drug (DMARD) anti-TNF covered by the Brazilian Public Healthcare System in cases of persistence of moderate/high disease activity after 6 months with at least two different therapeutic regimens with synthetic DMARD. The patient support program Programa Compromisso Saúde (Health Compromise Program - HCP) was created to follow patients receiving CZP for rheumatoid arthritis (RA). This study aimed to verify whether follow-up of RA patients by HCP results in greater adherence to treatment with CZP.

\section{MATERIALS AND METHODS}

Deterministic linkage was performed between HCP database and Brazilian Health System claims database (DATASUS) to identify RA patients (ICD-10) that started CZP treatment in 2015 - 2018 to create two cohorts: (A) HCP cohort, patients followed by HCP and (B) non-HCP cohort, patients that are not. Adherence was measured by proportion of days covered (PDC), defined as the ratio between months with CZP therapy and the total follow up period. Patients were considered adherent to CZP when PCD $\geq 80 \%$. Discontinuation was assumed after three months with no CZP therapy.

\section{RESULTS}

After deterministic linkage, HCP cohort was comprised by 1,368 and non-HCP cohort by 454 patients. HCP cohort presented longer period of treatment (7.68 \pm 7.08 months vs $4.48 \pm 5.06$ months). Global adherence for both groups was compared and there was no statistical significance regarding proportion of patients with PDC $\geq 80 \%$ ( $88.16 \%$ vs $90.75 \%, p=0.13$ ). Considering the $6-12$ months follow-up, the proportion of adherent patients was higher in HCP cohort ( $82.1 \%$ vs $64.7 \%, p=0.005)$. No statistically significant differences were found for age groups for the follow-ups 0-6 months and more than 12 months $(p>0.05)$. Although follow-up was longer for HCP cohort $(8.77 \pm 8.32$ months vs $5.23 \pm 6.4$ months), as expected, statistical difference regarding discontinuation rate was observed only for the period of 6-12 months $(14.4 \%$ vs $31.37 \%, p=0.003)$.

\section{CONCLUSION}

Participation on HCP improved adherence and discontinuation rate on the follow up period of 6-12 months. The HCP had few information on patients, causing an overlap of patients after linkage between databases and limiting sample size. This evidences the need to collect more key information about patients to improve and update upcoming assessments. It is believed that an update of this study, comprising more patients in both groups will highlight the relevance of HCP on promoting adherence. 